\title{
A NEW LOW DISTORTION ANALOG MULTIPLIER
}

\author{
Riza Can TARCAN ${ }^{1}$ Hakan KUNTMAN ${ }^{2}$ \\ 1,2 \\ Istanbul Technical University, Faculty of Electrical and Electronics Engineering, Department of Electronics \\ and Communication Eng., 80626, Maslak, İstanbul, TURKEY \\ Fax: +90-212-285 3679 \\ 'e-posta:rizacan@ehb.itu.edu.tr_2e-posta:kuntman@ehb.itu.edu.tr
}

Key Words: Circuits and Systems, Analog Multipliers, Short Channel Effect, Linearity

\begin{abstract}
A new method has been proposed to reduce the mobility degradation effect on square-law characteristic of the MOS transistor. This method has been applied to an analog multiplier to form a new low distortion multiplier circuit. This analog multiplier operates with $\pm 5 \mathrm{~V}$ power supply. The operating range for each input is $\pm 3 \mathrm{~V}$. In this operating range the nonlinearity for $V x$ is $0.6 \%$ and for $V y$ is $0.5 \%$. The $3 \mathrm{~dB}$ bandwidth is specified for $V x$ as $33 \mathrm{MHz}$ and for $\mathrm{Vy}$ as $34 \mathrm{MHz}$, respectively.
\end{abstract}

\section{INTRODUCTION}

Analog multipliers are the key elements of signal processing circuits. There are several techniques of implementing four quadrant multipliers including techniques based on square-law characteristic of the MOS transistor operating in the saturation region. Several second order effects influencing the linearity of multiplier circuits are reported in the literature [17]. Mobility degradation caused by short channel effect is the most important factor which degrades the linearity of this kind of multipliers. Althought there are several analog multipler circuits [1-7] based on squarelaw characteristic of MOS transistor, in none of them any special precaution has been introduced to reduce the short channel effect. In this work a new method has been proposed for reducing the mobility degradation effect on square-law characteristic of the MOS transistor. This method has been applied to an analog multiplier [1] to form a new low distortion multiplier circuit. This analog multiplier operates with $\pm 5 \mathrm{~V}$ power supply. The operating range for each input is $\pm 3 \mathrm{~V}$. In this operating range the nonlinearity for $\mathrm{Vx}$ is $0.6 \%$ and for $\mathrm{Vy}$ is $0.5 \%$. The $3 \mathrm{~dB}$ bandwidth is specified for $\mathrm{Vx}$ as $33 \mathrm{MHz}$ and for $\mathrm{Vy}$ as $34 \mathrm{MHz}$, respectively.

\section{METHOD TO REDUCE THE SHORT CHANNEL EFFECT}

The method for linearization of the square-law characteristic of MOS transistor is shown in the circuits of Figure-1a and Figure-1b. T3 is the main squaring transistor in Figure-1a and Figure-1b. T1, T2, $\mathrm{R}$ and current mirror CM in Figure-1a and T1, T2, R in Figure-1b realize Eq.(1).

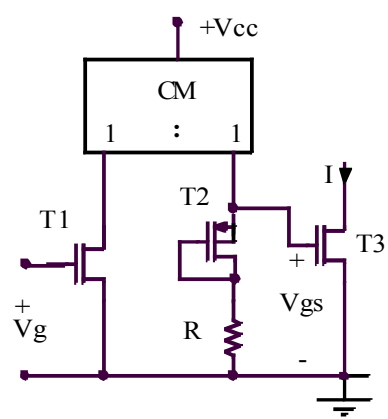

(a)

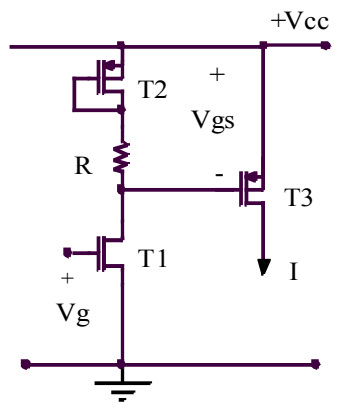

(b)
Figure-1. Linearization of the square-law characteristic of MOS transistor

$V g s=V g+k\left(V g-V_{T}\right)^{2}$

Since mobility degradation of NMOS transistor is less than that of the PMOS transistor, the circuit in Figure1a has been used in proposed multiplier circuit.

By a proper choose of $\mathrm{k}$ in Eq.(1) squaring error can be minimized. The drain current I of T3 of in Figure1a can be expressed as

$I=\frac{\beta}{2} \frac{\left(V g s-V_{T}\right)^{2}}{1+\theta\left(V g s-V_{T}\right)}$

where $\theta$ parameter models the short channel effect in SPICE LEVEL-3 Model.

Using Eq.(1) and Eq.(2), we can get

$I=\frac{\beta}{2} V_{x}^{2} \frac{1+2 k V_{x}+k^{2} V_{x}^{2}}{1+\theta V_{x}+\theta k V_{x}^{2}}$

where $\mathrm{V}_{\mathrm{x}}$ is defined as

$V_{x}=V g-V_{T}$

Assuming $\mathrm{k}=\mathrm{n} \theta$ and choosing $\mathrm{n}=1 / 2$ Eq.(3) converts to

$I=\frac{\beta}{2} V_{x}^{2} \frac{1+\theta V_{x}+\left(\theta^{2} / 4\right) V_{x}^{2}}{1+\theta V_{x}+\left(\theta^{2} / 2\right) V_{x}^{2}}$

Since $\theta<<1$ we can easily omit $\theta^{2}$ and we get from Eq.(5) 
$I \approx \frac{\beta}{2} V_{x}^{2}$

The main factor that degrades the operation of the circuit in Figure-1a and Figure-1b is the short channel effect of T1 and T2, which are modeled with $\theta_{1}$ and $\theta_{2}$, respectively. The expression of Vgs including $\theta_{1}, \theta_{2}$ for $\beta_{1}=\beta_{2}=\beta$ is shown in Eq.(7) where $\mathrm{k}$ is defined in Eq.(8).

$V g s=V g+k \frac{\left(V g-V_{T}\right)^{2}}{1+\theta_{1}\left(V g-V_{T}\right)}$

$k=\frac{\beta}{2}\left(R+\frac{\theta_{2}}{\beta}-\frac{\theta_{1}}{\beta}\right)$

For $\theta_{1}=\theta$ and $\mathrm{k}=\mathrm{n} \theta$, the full equation of the drain current I defined by

$I=\frac{\beta}{2} V_{x}^{2} \cdot E$

where $\mathrm{V}_{\mathrm{x}}=\mathrm{Vg}-\mathrm{V}_{\mathrm{T}}$ and $\mathrm{E}$ is expressed as

$$
E=\frac{\left(1+\theta(1+n) V_{x}+\theta^{2}(1+n)^{2} V_{x}^{2}\right)}{\left(1+\theta V_{x}\right)\left(1+2 \theta V_{x}+\theta^{2}(1+n) V_{x}^{2}\right)}
$$

To show the effect of the quantity $\mathrm{n}$ on linearization, relative error function E-1 is drawn in Figure-2 for $\theta=0.3$.

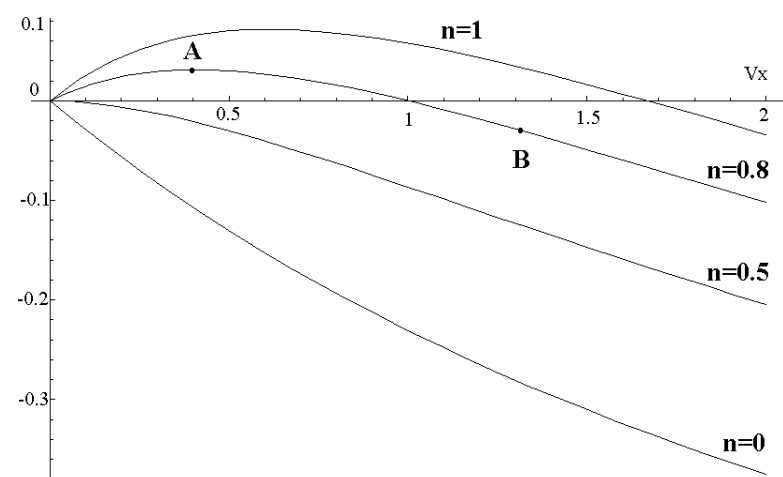

Figure-2. Relative errors of E-1 for several $n(\theta=.3)$

For $\mathrm{n}=0$ the circuit behaves as described in Eq.(2). Increasing $\mathrm{n}$ also reduces the relative error. In point $\mathrm{A}$ the maximum relative error becomes $\mathrm{e}$ and in point $\mathrm{B}(\mathrm{Vx}=\mathrm{Vxm})$ the relative error becomes $-\mathrm{e}$. Using the properties of these points, the maximum input range Vxm for a given relative error $|\mathrm{h}|$ can be derived from Eq.(10) as

$V x m \approx \frac{\sqrt{8 e}+3 e+\sqrt{e(16+12 \sqrt{2 e}+e)}}{4 \theta(1-e)}$

where $\mathrm{e}=|\mathrm{h}|$. In that case, $\mathrm{n}$ must be chosen as $\mathrm{n} \approx \frac{1+\sqrt{8 e}}{2}$

To obtain the required $n, R$ and $\beta$ must be chosen according to Eq.(8) where $\mathrm{k}=\mathrm{n} \theta$.

\section{THE CONCEPT OF THE MULTIPLIER CIRCUIT}

In the proposed analog multiplier [1], circuit in Figure3 has been taken into consideration but transistors $\mathrm{T} 1, \mathrm{~T} 2, \mathrm{~T} 3$ and $\mathrm{T} 4$ are replaced with circuit in Figure1a. An adequate value of $\mathrm{k}$ is selected to minimize the harmonic distortion.

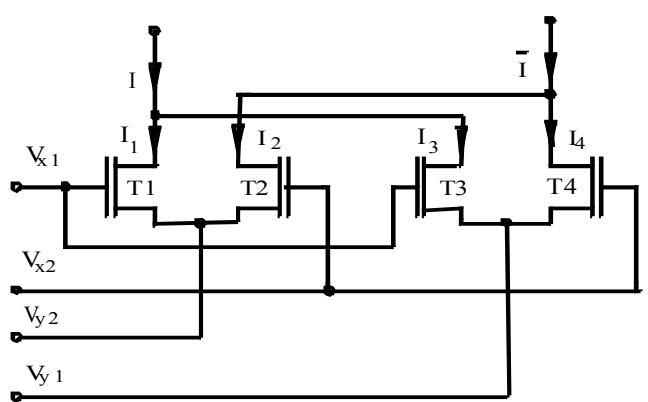

Figure-3. Conventional multiplier circuit

Using Eq.(2) and considering short channel effect for each of the transistor in Figure-3, the output current $\mathrm{Io}=\mathrm{I}_{1}-\mathrm{I}_{2}-\left(\mathrm{I}_{3}-\mathrm{I}_{4}\right)$ can be expressed as

$I-\bar{I}=\frac{\beta \cdot V_{D X} \cdot V_{D Y} \cdot a}{a^{4}-a^{2} \frac{\theta^{2}}{2}\left(V_{D X}^{2}+V_{D Y}^{2}\right)+\frac{\theta^{4}}{16}\left(V_{D X}^{2}-V_{D Y}^{2}\right)^{2}}$

where $\mathrm{V}_{\mathrm{DX}}, \mathrm{V}_{\mathrm{DY}}, \mathrm{V}_{\mathrm{CX}}, \mathrm{V}_{\mathrm{CY}}$ and are defined as

$V_{X 1^{-}} V_{X 2}=V_{D X}, V_{Y 2^{-}} V_{Y 1}=V_{D Y}, V_{X 1}+V_{X 2}=V_{C X}$

$V_{Y 1}+V_{Y 2}=V_{C Y}, a=1+\theta / 2\left(V_{C X}-V_{C Y}-2 V_{T}\right)$

Ignoring $\theta$ in Eq.(13), ideal multiplication formula is obtained as

$I o=I-\bar{I}=B \cdot V_{D X} . V_{D Y}$

Ignoring $\theta^{4}$ in the denominator, the serial expansion of Eq.(13) will be

$$
\begin{aligned}
& I o=\beta V_{D X} V_{D Y} \frac{1}{a^{3}}\left[1+\frac{\theta^{2}}{2 a^{3}}\left(V_{D X}^{2}+V_{D Y}^{2}\right)+\right. \\
& \left.\frac{\theta^{4}}{4 a^{4}}\left(V_{D X}^{2}+V_{D Y}^{2}\right)^{2}+\frac{\theta^{6}}{8 a^{6}}\left(V_{D X}^{2}+V_{D Y}^{2}\right)^{4}+\ldots\right]
\end{aligned}
$$

It can be clearly seen that the harmonic distortion is produced by high-order components of $\mathrm{V}_{\mathrm{DX}}$ and $\mathrm{V}_{\mathrm{DY}}$ caused by $\theta$. 
Eq.(9) is valid for each transistor in the proposed circuit. Neglecting $\theta^{2}$ in the parentheses of the numerator and the denominator of Eq.(10) we can get Eq.(17) and Eq.(18).

$$
\begin{aligned}
I & \approx \frac{\beta}{2} V_{x}^{2} \frac{1+2 \theta(1+n) V_{x}}{\left(1+\theta V_{x}\right)\left(1+2 \theta V_{x}\right)} \\
& \approx \frac{\beta}{2} V_{x}^{2}\left[\frac{(1+2 n)}{\left(1+\theta V_{x}\right)}-\frac{2 n}{\left(1+2 \theta V_{x}\right)}\right]
\end{aligned}
$$

At this point utilizing Eq.(18) for each transistor, the new multiplication equation can be obtained as

$$
I=\beta . V_{D X} \cdot V_{D Y}\left[\frac{1+2 n}{a^{3}-a \frac{\theta^{2}}{2} z}-\frac{2 n}{b^{3}-2 b \theta^{2} z}\right]
$$

where $a, b, z$ are defined by

$$
\begin{aligned}
& a=1+\theta / 2\left(V_{C X}-V_{C Y}-2 V_{T}\right) \\
& b=1+\theta\left(V_{C X}-V_{C Y}-2 V_{T}\right) \\
& z=V_{D X}^{2}+V_{D Y}^{2}
\end{aligned}
$$

The serial expansion of Eq.(19) gives

$$
\begin{aligned}
& I o=\beta V_{D X} V_{D Y}\left[\frac{1+2 n}{a^{3}}-\frac{2 n}{b^{3}}+\theta^{2}\left(\frac{(1+2 n)}{2 a^{5}}-\frac{8 n}{2 b^{5}}\right)\left(V_{D X}^{2}+V_{D Y}^{2}\right)+\right. \\
& \left.+\theta^{4}\left(\frac{(1+2 n)}{4 a^{7}}-\frac{32 n}{4 b^{7}}\right)\left(V_{D X}^{2}+V_{D Y}^{2}\right)^{2} \ldots\right]
\end{aligned}
$$

It is clearly seen that the third harmonic distortion created by $V_{D X}^{2}$ and $V_{D Y}^{2}$ in the parenthesis can be cancelled selecting $\mathrm{n}$ as

$$
n=\frac{b^{5}}{8 a^{5}-2 b^{5}}
$$

Since $\theta<1$, then $a \approx 1$ and $b \approx 1$. So Eq.(22) yields $1 / 6$. This shows that the new circuit makes it possible to minimize the distortion by controlling $\mathrm{n}$ via $\mathrm{k}(\mathrm{k}=\mathrm{n} \theta)$.

\section{DESCRIPTION OF THE HIGH LINEARITY ANALOG MULTIPLIER}

The complete multiplier circuit is illustrated in Figure4. The output current Io is produced from the current I and $\bar{I}$ by the output stage given in Figure-5. The inputs voltages $\mathrm{V}_{\mathrm{X} 1}, \mathrm{~V}_{\mathrm{X} 2}, \mathrm{~V}_{\mathrm{Y} 1}$ and $\mathrm{V}_{\mathrm{Y} 2}$ are generated from active attenuator circuit shown in Figure-6. The subcircuits composed of M17-M22 and CM1, M23M28 and CM2, M29-M34 and CM3, M35-M40 and CM4, operate like the circuit in Figure-1a. M20, M26, M32 and M37 operate in triode region to simulate the resistor R shown in Figure-1a. M17, M21, M23, M27, M29, M33, M35 and M40 have larger aspect ratios than that of the transistors M18, M22, M24, M28, M30, M34, M36 and M39 to allow them operating in saturation region. For this reason, the channel length modulation of the M18, M22, M24, M28, M30, M34, M36, M39 on multiplication process is reduced. On the other hand M41 and M42 provide the bias of the transistors M18, M28, M30 and M39 so that $\mathrm{V}_{\mathrm{GS}}-\mathrm{V}_{\mathrm{T}}>0$ is obtained for M18, M28, M30 and M39 in full operating range of $\mathrm{V}_{\mathrm{DX}}$ and $\mathrm{V}_{\mathrm{DY}}$. The subcircuits consisting of M43, M44, Ic3 and M45, M46, Ic4 form two buffers; one between M18, M30 and Vy2 the other between M28, M39 and Vy1.

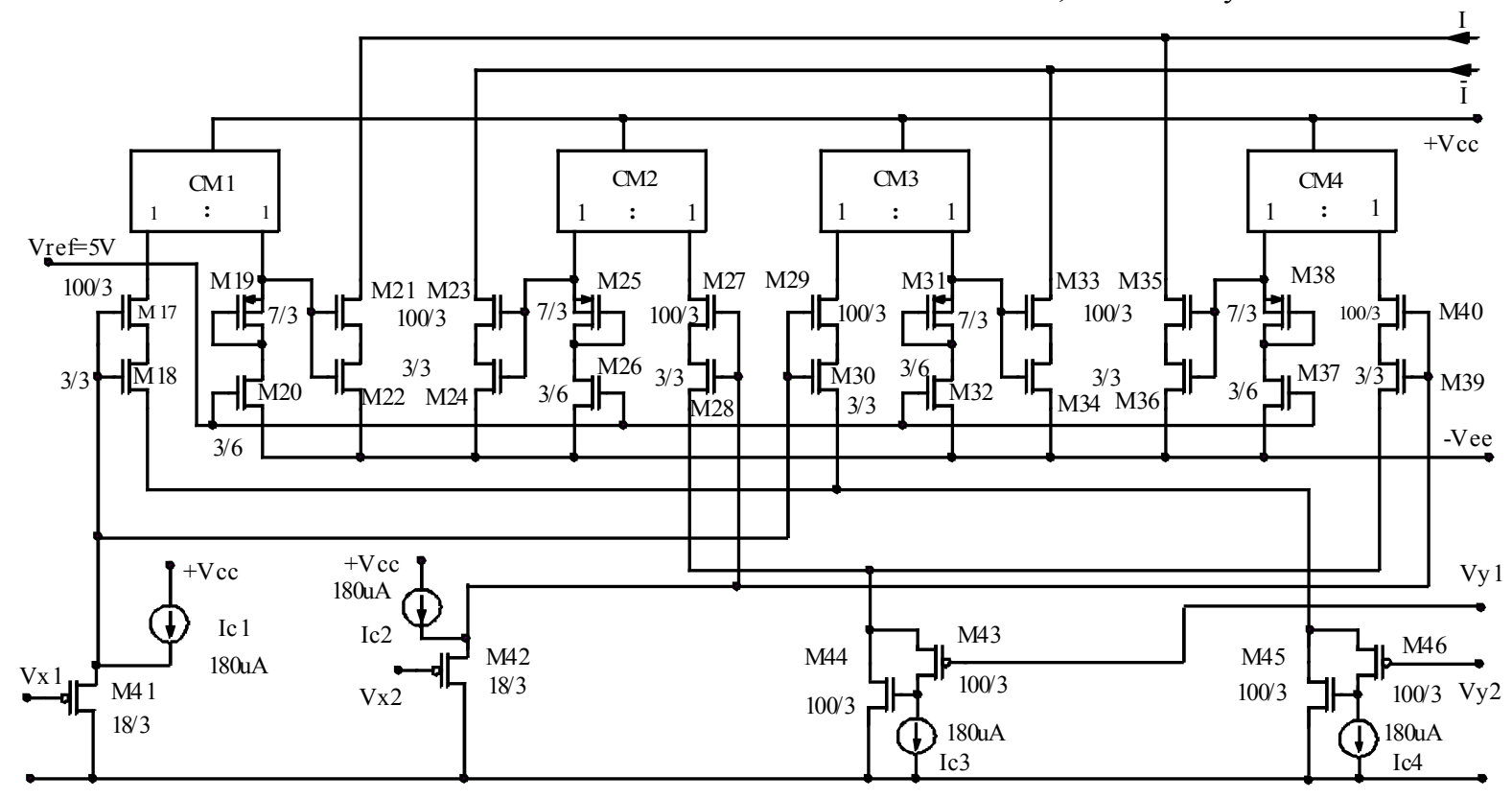

Figure-4.The high-linearity analog multiplier 


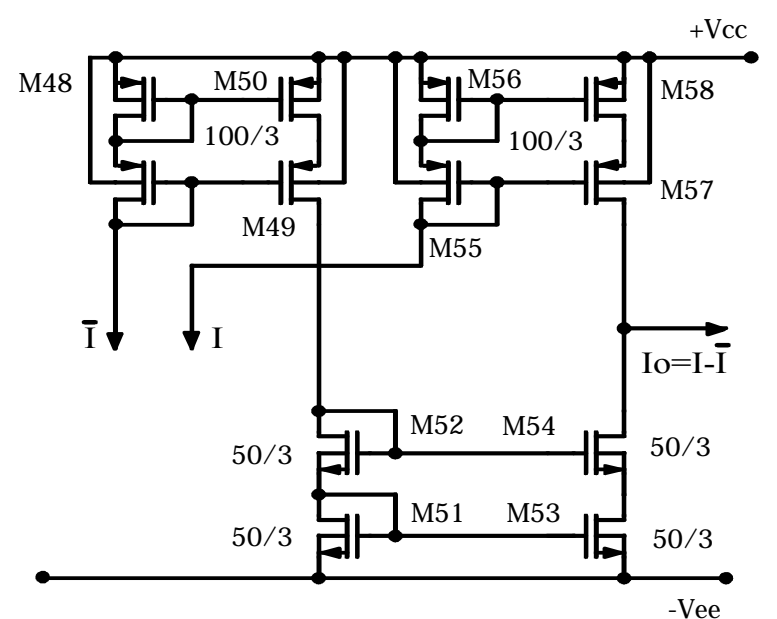

Figure-5. The output circuit

\section{ACTIVE ATTENUATOR CIRCUIT}

Active attenuator circuit has been discussed in [8]. This circuits generates $\mathrm{V}_{\mathrm{X} 1}, \mathrm{~V}_{\mathrm{X} 2}, \mathrm{~V}_{\mathrm{Y} 1}$, and $\mathrm{V}_{\mathrm{Y} 2}$ so that we obtain $\mathrm{V}_{\mathrm{X} 1}-\mathrm{V}_{\mathrm{X} 2}=\mathrm{K}\left(\mathrm{V}_{\mathrm{X}}-\overline{\mathrm{V}}_{\mathrm{X}}\right), \mathrm{V}_{\mathrm{Y} 1}-\mathrm{V}_{\mathrm{Y} 2}=\mathrm{K}\left(\mathrm{V}_{\mathrm{Y}}-\overline{\mathrm{V}}_{\mathrm{Y}}\right)$. They not only reduce distortion but also make the voltages $\mathrm{V}_{\mathrm{X} 1}, \mathrm{~V}_{\mathrm{X} 2}$ and $\mathrm{V}_{\mathrm{Y} 1}, \mathrm{~V}_{\mathrm{Y} 2}$ independent from input bias conditions. Active attenuator circuit $\mathrm{X}$ is shown in Figure-6. Active attenuator circuit $\mathrm{Y}$ is the same but only transistor numbers are between M9M16. In Figure-6 transistors M1-M4 form a differantial pair. Aspect ratio of M3 and M4 are chosen sufficient large to allow M1 and M2 operating in saturation region. In this case, conductance of the differential pair is determined by M1 and M2 but the output impedance of circuit becomes much larger than conventional differential pair. On the other hand M7 and M8 are operating in triode region and simulate resistor $\mathrm{Rd}$. This resistor $\mathrm{Rd}$ is used to cancel the distortion caused by the short channel effects of the transistors.

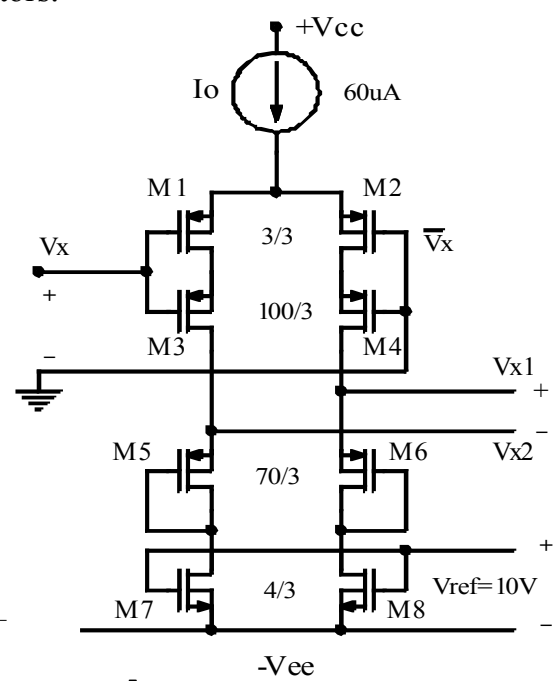

Figure-6. Active attenuator for the inputs $\mathrm{X}$ and $\mathrm{Y}$

This resistor $\mathrm{Rd}$ is defined as
$\operatorname{Rd}=\theta\left(\frac{1}{\sqrt{\beta_{1} \beta_{2}}}-\frac{1}{\beta_{2}}\right)$

where $\beta_{1}$ is the conductance of M1, M2 and $\beta_{2}$ is the conductance of M5, M6 and $\theta$ is the short channel effect of PMOS.

For Rd specified in Eq.(23) attenuations for inputs $\mathrm{X}$ and $\mathrm{Y}$ are defined by

$\mathrm{V}_{\mathrm{X} 2}-\mathrm{V}_{\mathrm{X} 1}=\sqrt{\left(\frac{\beta_{1}}{\beta_{2}}\right)} \cdot(V x-\bar{V} x)$
$\mathrm{V}_{\mathrm{Y} 2}-\mathrm{V}_{\mathrm{Y} 1}=\sqrt{\left(\frac{\beta_{1}}{\beta_{2}}\right)} \cdot(V y-\bar{V} y)$

To obtain a required value $\mathrm{Rd}$, conductance of $\mathrm{M} 7$ and M8 must be selected as

$\beta_{78}=\frac{1}{\operatorname{Rd}\left(\operatorname{Vref}-V_{T}\right)}$

\section{SIMULATIONS}

In the simulation SPICE Level-3 parameters of TÜBITAK $3 \mu$ process are used. The circuit is supplied with $\pm 5 \mathrm{~V}$. Input ranges of $\mathrm{X}$ and $\mathrm{Y}$ is $\pm 3 \mathrm{~V}$. The simulated resistors $\mathrm{R}$ and $\mathrm{Rd}$ described above are chosen as $11 \mathrm{~K} \Omega$ and $5 \mathrm{~K} \Omega$, respectively. To get a comparison, simulations are performed for optimized case $\left(\mathrm{k}=\mathrm{k}_{\mathrm{opt}}=1 / 6\right)$ providing minimum distortion and for nonoptimized case $(\mathrm{k}=0)$ where the circuit behaves similar to multiplier in Figure-3. Figure-7 shows several Io-Vx curves obtained by taking $\mathrm{Vy}$ as parameter in the optimized case and Figure- 8 shows linearity errors of the curves in Figure-7. On the other hand Figure-9 shows several Io-Vx curves for obtained by taking $\mathrm{Vx}$ as parameter in the nonoptimized case and Figure-10 shows the linearity errors of the curves in Figure-8. In the optimized case linearity error becomes $0.6 \%$ whereas $15 \%$ for the nonoptimized case. The circuit is also tested by applying $100 \mathrm{KHz}$ sinusoidal signal with $6 \mathrm{Vpp}$. The total harmonic distortion has been determined as $0.2 \%$ for the optimized case whereas $1 \%$ for the nonoptimized case. Similar results have been also observed for input $\mathrm{Vy}$ under the same simulation conditions. In this case total linearity error is $0.5 \%$ for the optimized condition and $8 \%$ for the nonoptimized condition. On the other hand total harmonic distortion is $0.2 \%$ for optimized case and $0.7 \%$ for nonoptimized case. The $-3 \mathrm{~dB}$ frequency bandwidth of inputs $\mathrm{X}$ and $\mathrm{Y}$ are $33 \mathrm{MHz}$ and $34 \mathrm{Mhz}$, respectively. The results show that the proposed linearization method is robust. Other important property of the circuit is that an external control on distortion can be made by changing Vref in Figure-3. 


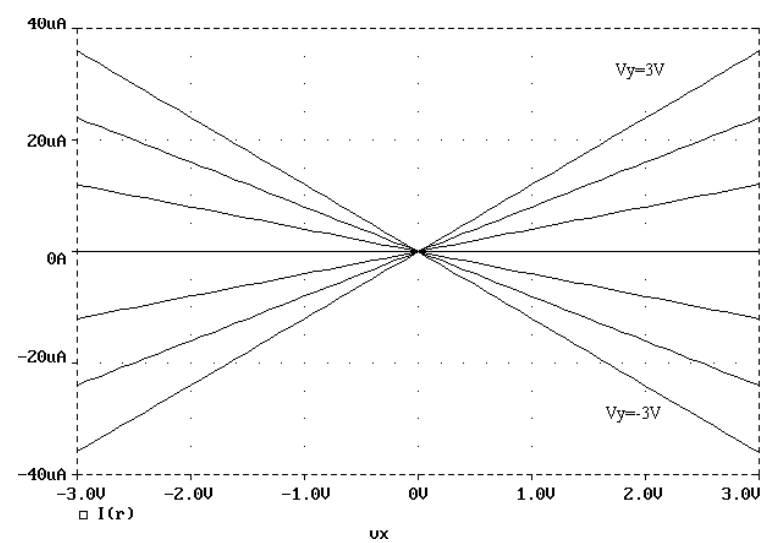

Figure-7. Io-Vx curves for $\mathrm{k}=\mathrm{k}_{\mathrm{opt}}$

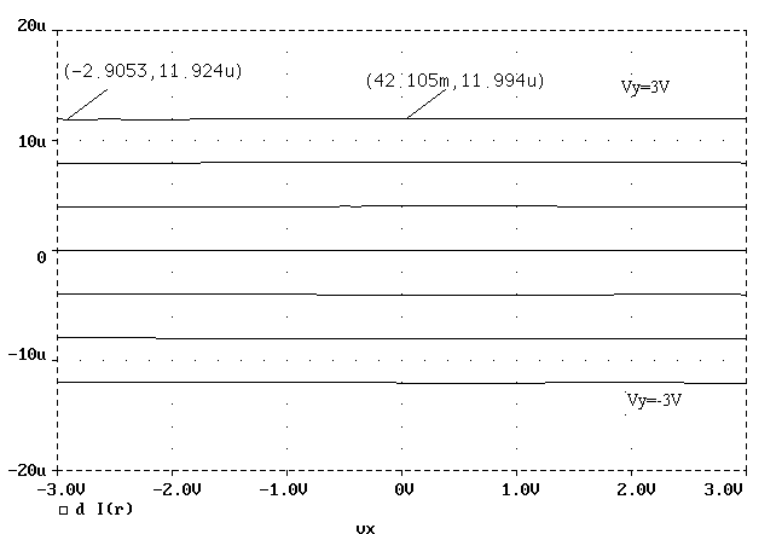

Figure-8. Error performances of the curves in Figure-7

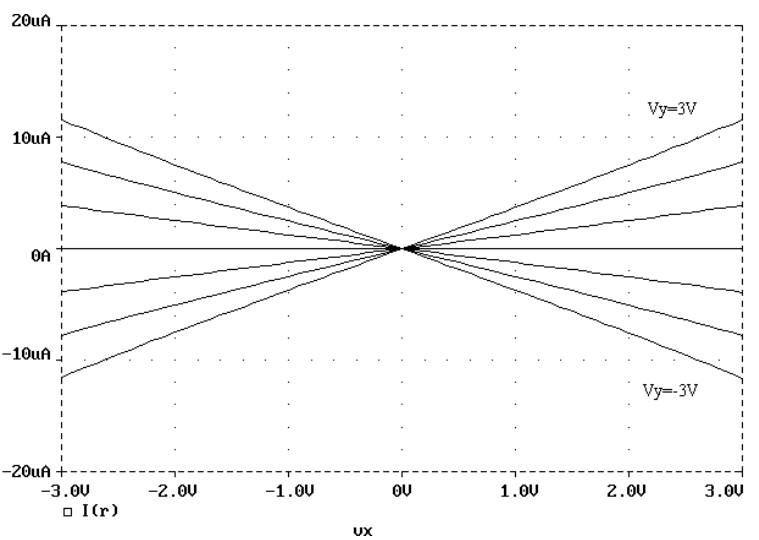

Figure-9. Io- $\mathrm{Vx}$ curves for $\mathrm{k}=0$

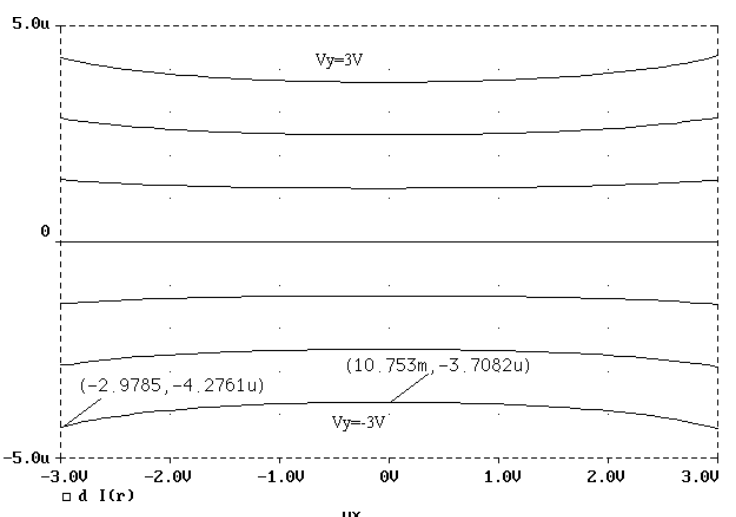

Figure-10.Error performances of the curves in Figure-9

\section{CONCLUSION}

A new method has been proposed to reduce the mobility degradation effect on square-law characteristic of MOS transistor. This method has been applied to an analog multiplier to form a new low harmonic distortion multiplier circuit. This analog multiplier operates with $\pm 5 \mathrm{~V}$ power supply. The operating range for each input is $\pm 3 \mathrm{~V}$. In this operating range the nonlinearity for $\mathrm{Vx}$ is $0.6 \%$ and for $\mathrm{Vy}$ is $0.5 \%$. The $3 \mathrm{~dB}$ bandwidth is specified for $\mathrm{Vx}$ as $33 \mathrm{MHz}$ and for $\mathrm{Vy}$ as $34 \mathrm{MHz}$, respectively. The multiplier topology proposed allows external adjustment of the distortion which can be considered as another important property of the circuit. The simulation results show that the new method is affective for reducing distortion.

\section{REFERENCES:}

[1] Shen-Iuan Liu and Chen-Chieh Chang, 'Low Voltage CMOS Four Quadrant Multiplier', Electronics Letters, Voll 33, No 3, pp 207-208, $30^{\text {Th }}$ January 1997.

[2] Hamid Reza Mehrvarz and Chee Yee Kwok,'A Novel Multi-Input Floating-Gate MOS FourQuadrant Analog Multiplier', IEEE Journal of Solid-State Circuits, Vol 31 No 8, pp 1123-1131, August 1996.

[3] Ho-Jun Song and Choong-Ki Kim, 'An MOS Four-Quadrant Analog Multiplier Using Simple Two-Input Squaring Circuits With Source Followers', IEEE Journal of Solid-State Circuits, Voll 25, No 3, pp 841-848, June 1990.

[4] Klaas Bult and Hans Wallinga, 'A CMOS FourQuadrant Analog Multiplier', IEEE Journal of Solid-State Circuits, Vol sc-21, No 3, pp 430-435, June 1986.

[5] Jesus S, Pena Finol and J. Alvin Conelly, 'A MOS Four-Quadarant Using The Quarter-Square Technique', IEEE Journal of Solid-State Circuits, Vol sc-22, No 6, pp 1064-1073, Dec 1987.

[6] Z. Hong and H. Melchior, 'Four-Quadrant Analog Multiplier', Electronics Letters, Voll 20, No 24, pp 1015-1016, $22^{\text {nd }}$ Nov 1984.

[7] LT and Wallinga, 'Analog CMOS Circuits Based on Square-Law Characteristic of MOS Tranzistor', IEEE journal of Solid-State Circuits, Vol 22 No 3, pp 357-365, June 1987.

[8] R. C. Tarcan, H. Kuntman, 'Düşük distorsiyonlu analog çarpma devresi', Bursa ElektrikElektronik-Bilgisayar Müh. Sempozyumu (ELECO 2000), Elektronik ve Bilgisayar Bildiri Kitab1, 72-76, EMO Bursa Şubesi, Bursa, 8-12 Kasim 2000. 